\title{
Genetic Diversity and Geographical Differentiation of Nipa (Nypa fruticans Wurmb.) Populations in Peninsular Malaysia Based on AFLP
}

\author{
Koji TSUJI ${ }^{1,2,5^{*}}$, Mohd. Norfaizal GHAZALLI ${ }^{3}$, Zulhairil ARIFFIN $^{3}$, \\ Mohd. Shukor NORDIN ${ }^{3}$, Maya Izar KHAIDIZAR ${ }^{3}$, \\ Mohammad Ehsan DULLOO ${ }^{4}$ and Leocadio S. SEBASTIAN ${ }^{1,6}$ \\ ${ }^{1}$ Bioversity International Regional Office for Asia, the Pacific and Oceania \\ (PO Box 236, UPM Post Office, Serdang, 43400 Selangor Darul Ehsan, Malaysia) \\ ${ }^{2}$ Fellow of Japan-CGIAR fellowship program \\ ${ }^{3}$ Strategic Resource Research Centre, Malaysian Agricultural Research and Development Institute \\ (MARDI) \\ (PO Box 12301, General Post Office 50774 Kuala Lumpur, Malaysia) \\ ${ }^{4}$ Bioversity International Headquarters \\ (Via dei Tre Denari 472/a, 00057 Maccarese, Rome, Italy)
}

\begin{abstract}
Nipa (Nypa fruticans Wurmb.) is a useful and widely distributed palm in Southeast Asia, but its habitats are declining due to industrial development. Information on genetic diversity, geographical differentiation, and phylogenetic relationships among the populations is important in order to develop conservation strategies for this species. In this study, the genetic diversity within and among 29 natural populations in Peninsular Malaysia was analyzed using the AFLP molecular technique. Polymorphism within a population was detected for 27 populations and three geographically distinct groups of nipa. The results showed that the highest frequency of heterozygosity was found in the west coast southern region, followed by the west coast northern region, and with the lowest frequency in the east coast region. In the phylogenetic tree, the three geographical regions that formed distinct groups with the west coast southern region group were located between the west coast northern region group and the east coast region. These results may suggest that nipa in Peninsular Malaysia has been diffused from or along the west coast southern region to the other regions. The three regional groups are differentiated genetically and it is recommended that all three regions should be targets for the conservation of nipa habitats, in order to reduce genetic erosion within the nipa in Peninsular Malaysia.
\end{abstract}

Discipline: Genetic resources

Additional key words: conservation, habitat, phylogenetic relationship

\section{Introduction}

Nipa (Nypa fruticans Wurmb.) is among the most common, widely distributed and useful palms found in the mangrove forests of Southeast Asia. In addition to favoring brackish water environments such as estuaries or shallow lagoons, nipa is also colonized at the upper tidal reaches of rivers, in the semi-liquid mud of estuaries, and along coastlines (Baja-Lapis et al. 2004, Burkill 1935, Corner 1966, Tomlinson 1986, Whitmore 1973). Nipa grows in clusters, often forming large colonies without visible stems above the ground. The underground stem

This paper reports the results obtained in the Japan-CGIAR fellowship program for Dr. Koji TSUJI titled "Characterization and evaluation of the genetic diversity of neglected and underutilized crops conserved in gene banks" and sponsored by the Japan International Research Center for Agricultural Sciences (JIRCAS), which is commissioned from Japan's Ministry of Agriculture, Forestry, and Fisheries (MAFF).

Present address:

${ }^{5}$ Faculty and Graduate School of Education, Chiba University (Chiba, Chiba 263-8522, Japan)

${ }^{6}$ IRRI-CCAFS Office (Agricultural Genetics Institute, Km 2 Pham Van Dong Ave, Tu Liem District, Hanoi, Vietnam)

${ }^{*}$ Corresponding author: e-mail tsujikoji684@chiba-u.jp

Received 10 September 2014; Accepted 8 May 2015. 
(called rhizome) lies horizontally underneath the ground and reaches about half a meter in length. At the end of the growing rhizome, a new plant rises, thereby adding to the cluster in the colony. In addition to its vegetative propagation, nipa also propagates through seed germination (Baja-Lapis et al. 2004).

Nipa has historically provided useful products to indigenous peoples living near or in the coastal and estuarine mangrove forest area (Hamilton \& Murphy 1988, Päiväke 1996). Matured leaves have been used for roof thatching, the wall-partitioning of dwellings, roofs of boats, umbrellas, sun hats, raincoats, baskets, mats and bags, and young leaves are made into cigarette wrappers and to wrap cooked rice (Baja-Lapis et al. 2004, Burkill 1935, Fong 1984, Fong 1992, Hamilton \& Murphy 1988, Ilias et al. 2002, Päiväke 1996, Robillos 1978). Petioles are used as the floats for fishnets (Fong 1984, Fong 1992) and arrows (Burkill 1935). Young seeds and buds of the stem are edible (Burkill 1935, Hamilton \& Murphy 1988, Whitmore 1973). One of the traditional prescriptions for treating herpes is drinking the juice from the young shoots with coconut milk (Burkill 1935). The sap of the fruit stalk is used as juice, vinegar, and fermented drink (Baja-Lapis et al. 2004, Burkill 1935, Fong 1984, Fong 1992, Hamilton \& Murphy 1988, Ilias et al. 2002, Päiväke 1996, Robillos 1978, Robinson 1911). The sap is also a useful source of biofuel because it is available as ethanol. Nipa can produce more ethanol than sugar cane (6,480-10,224 L/hectare/year vs. 3,350-6,700 L/hectare/ year) (Hamilton \& Murphy 1988). In addition, nipa is useful agriculturally and ecologically because its habitat does not compete with food crops, and its growth is sustainable (Hamilton \& Murphy 1988).

Peninsular Malaysia is one of the regions where nipa habitats are common, but such habitats are decreasing due to ongoing industrial development. Consequently, there is a need to develop a conservation strategy to protect nipa habitats from further decline. In this respect, gathering information on genetic diversity, geographical differentiation, and phylogenetic relationships among the natural populations is important. A previous study conducted on 183 individuals of six nipa populations in Vietnam, Thailand, and southern China using SSR and ISSR markers revealed low polymorphism among the populations (Jian et al. 2010). In this report, no polymorphism was detected within a population by ISSR markers and only one out of five populations showed polymorphism within a population by using 17 SSR markers. In addition, RAPD markers only revealed low polymorphism within a population of nipa on Iriomote Island (Setoguchi et al. 1999). In this report, only one out of 28 individuals showed polymorphism by 136 loci. By referring to these reports in order to reveal the genetic diversity of nipa populations, we decided to employ other DNA markers to detect high levels of polymorphism. AFLP has proven to be a good molecular method in the detection of high levels of polymorphism (Vos et al. 1995). In this study, we employed AFLP markers to assess the genetic diversity and geographical differentiation of nipa populations in Peninsular Malaysia, with a view to develop a conservation strategy for the protection of nipa habitats.

\section{Materials and Methods}

\section{Plant materials}

In order to collect nipa samples, we visited 10 out of the 11 states in Peninsular Malaysia (Fig. 1). We did not visit Kelantan state (east coast) due to time limitations for our field survey. We focused on coastlines, estuaries, and the upper tidal reaches of rivers, mainly based on past reports on nipa habitats (Baja-Lapis et al. 2004, Burkill 1935, Corner 1966, Tomlinson 1986, Whitmore 1973). Except in the states of Selangor and Negeri Sembilan, plenty of nipa habitats were observed along coastlines, in estuaries, and upper tidal reaches. We could not observe any nipa habitats in inland areas of Peninsular Malaysia. These observations on nipa habitat distribution in Peninsular Malaysia coincide with Global Land Survey data and Landsat archives on the mangrove forests of the world (Giri et al. 2011).

Fig. 1 shows a detailed map of Peninsular Malaysia, and Table 1 lists the plant materials used in this study. In total, 29 natural populations collected during our field survey on nipa habitats in Peninsular Malaysia were used. The 29 populations were classified into three geographical groups in this study - the west coast northern region (Perlis, Kedah, Penang, Perak, and Selangor states), the west coast southern region (Melaka and Johor states), and the east coast (Terengganu and Pahang states). The distance between the samples collected was more than 20 $\mathrm{m}$. Three individuals were randomly selected from each population for the AFLP experiment. However, only one individual was selected from population No. 2 because all individuals in the habitat were believed to be clones, due to the small population size (about $5 \mathrm{~m} \times 10 \mathrm{~m}$ ) and the fact that nipa plants predominantly adopt vegetative propagation. In addition, only two individuals were used from population No. 20 and No. 27 for data analyses as AFLP fingerprinting of the third individual showed extremely poor resolution and was considered unreliable. 


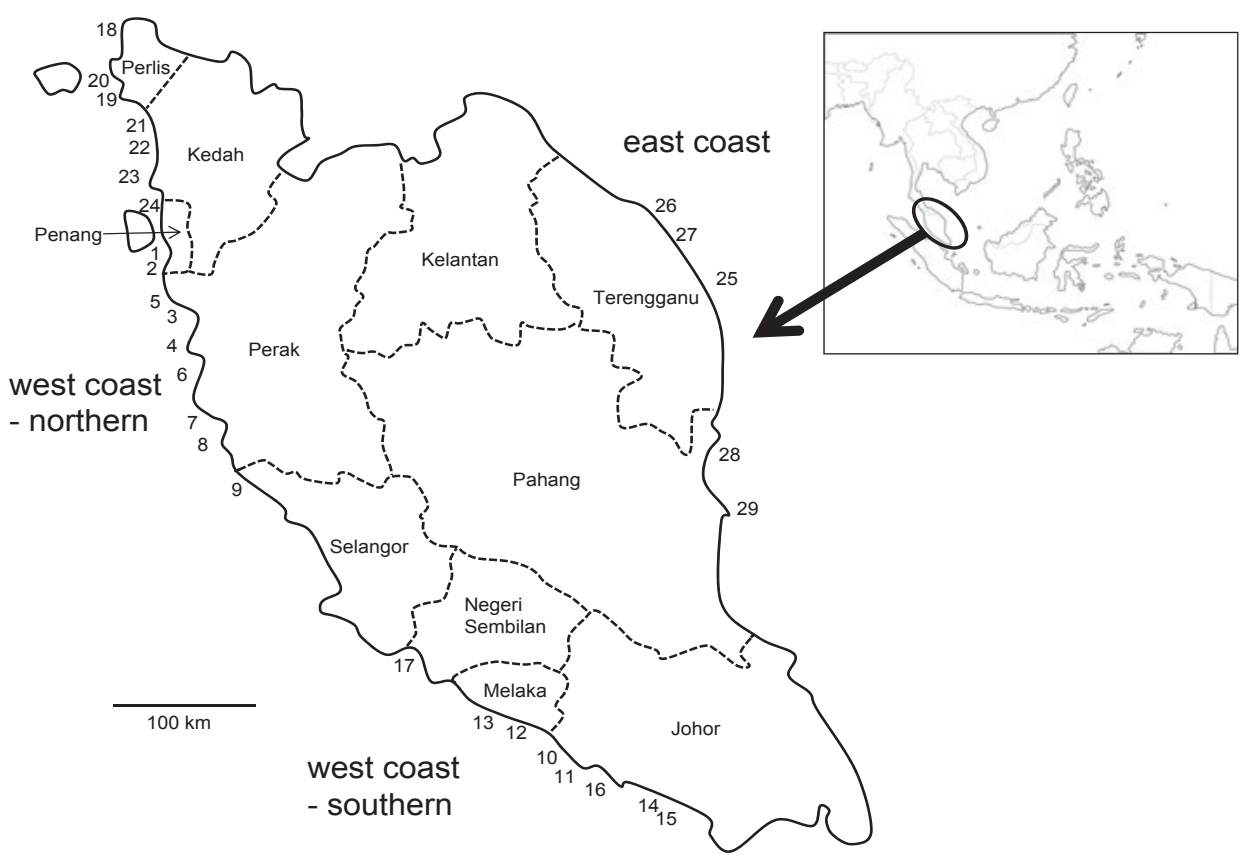

Fig. 1. Locations of the 29 populations used.

Table 1. Populations used in this study and polymorphic loci within a population

\begin{tabular}{|c|c|c|c|c|c|c|c|}
\hline $\begin{array}{c}\text { Serial } \\
\text { No. }\end{array}$ & Region & Province & Latitude & Longitude & $\begin{array}{c}\text { Number of individuals } \\
\text { used }\end{array}$ & $\begin{array}{c}\text { Number of } \\
\text { polymorphic loci within } \\
\text { a population }\end{array}$ & $\begin{array}{c}\% \text { of polymorphic loci } \\
\text { within a population }\end{array}$ \\
\hline 1 & west coast-northern & Penang & $\mathrm{N} \mathrm{05,09,029}$ & E $100,27,784$ & 3 & 0 & 0.00 \\
\hline 2 & west coast-northern & Penang & N 05, 08, 839 & E $100,25,446$ & 1 & & \\
\hline 3 & west coast-northern & Perak & $\mathrm{N} 04,59,182$ & E $100,26,820$ & 3 & 3 & 1.24 \\
\hline 4 & west coast-northern & Perak & $\mathrm{N} 04,50,438$ & E $100,38,743$ & 3 & 3 & 1.24 \\
\hline 5 & west coast-northern & Perak & $\mathrm{N} \mathrm{05,00,617}$ & E $100,25,860$ & 3 & 3 & 1.24 \\
\hline 6 & west coast-northern & Perak & $\mathrm{N} \mathrm{04,} 02,619$ & E $100,49,326$ & 3 & 6 & 2.48 \\
\hline 7 & west coast-northern & Perak & $\mathrm{N} \mathrm{04,} \mathrm{02,} 308$ & E $100,54,793$ & 3 & 2 & 0.83 \\
\hline 8 & west coast-northern & Perak & $\mathrm{N} \mathrm{03,57,940}$ & E $100,52,327$ & 3 & 3 & 1.24 \\
\hline 9 & west coast-northern & Selangor & $\mathrm{N} \mathrm{03,46,138}$ & E $100,58,768$ & 3 & 8 & 3.31 \\
\hline 18 & west coast-northern & Perlis & $\mathrm{N} 06,21,888$ & E $100,08,634$ & 3 & 8 & 3.31 \\
\hline 19 & west coast-northern & Perlis & $\mathrm{N} \mathrm{06,20,348}$ & E $100,10,815$ & 3 & 8 & 3.31 \\
\hline 20 & west coast-northern & Perlis & $\mathrm{N} 06,16,155$ & E $100,11,087$ & 2 & 5 & 2.07 \\
\hline 21 & west coast-northern & Kedah & N 06, 03, 932 & E $100,21,998$ & 3 & 6 & 2.48 \\
\hline 22 & west coast-northern & Kedah & $\mathrm{N} 06,52,250$ & E $100,23,085$ & 3 & 14 & 5.79 \\
\hline 23 & west coast-northern & Kedah & $\mathrm{N} 06,34,470$ & E $100,22,039$ & 3 & 6 & 2.48 \\
\hline 24 & west coast-northern & Penang & $\mathrm{N} 05,25,456$ & E $100,25,625$ & 3 & 4 & 1.65 \\
\hline 10 & west coast-southern & Johor & $\mathrm{N} 02,02,602$ & E $102,32,851$ & 3 & 22 & 9.09 \\
\hline 11 & west coast-southern & Johor & $\mathrm{N} \mathrm{01,59,670}$ & E $102,35,558$ & 3 & 4 & 1.65 \\
\hline 12 & west coast-southern & Melaka & $\mathrm{N} \mathrm{02,07,477}$ & E $102,30,140$ & 3 & 6 & 2.48 \\
\hline 13 & west coast-southern & Melaka & $\mathrm{N} 02,07,564$ & E $102,25,416$ & 3 & 17 & 7.02 \\
\hline 14 & west coast-southern & Johor & $\mathrm{N} \mathrm{01,} \mathrm{45,} 037$ & E $103,00,270$ & 3 & 21 & 8.68 \\
\hline 15 & west coast-southern & Johor & $\mathrm{N} 01,44,460$ & E $103,03,258$ & 3 & 13 & 5.37 \\
\hline 16 & west coast-southern & Johor & $\mathrm{N} \mathrm{01,} \mathrm{58,} 021$ & E $103,37,253$ & 3 & 23 & 9.50 \\
\hline 17 & west coast-southern & Melaka & $\mathrm{N} \mathrm{02,23,340}$ & E $101,58,730$ & 3 & 17 & 7.02 \\
\hline 25 & east coast & Terengganu & $\mathrm{N} 04,47,293$ & E $103,24,134$ & 3 & 12 & 4.96 \\
\hline 26 & east coast & Terengganu & $\mathrm{N} \mathrm{05,08,475}$ & E $103,14,644$ & 3 & 3 & 1.24 \\
\hline 27 & east coast & Terengganu & $\mathrm{N} 05,01,128$ & E $103,18,276$ & 2 & 7 & 2.89 \\
\hline 28 & east coast & Pahang & $\mathrm{N} 03,47,874$ & E $103,20,306$ & 3 & 10 & 4.13 \\
\hline 29 & east coast & Pahang & $\mathrm{N} \mathrm{03,31,877}$ & E $103,07,236$ & 3 & 8 & 3.31 \\
\hline
\end{tabular}




\section{DNA extraction}

The young leaves were kept at $-20^{\circ} \mathrm{C}$ after collection from the habitats. About one to two months following collection, DNA was extracted in MARDI's laboratory for molecular analysis by using the milky or light brown inner parts of young leaves. Grinding was performed using mortar and pestle with liquid nitrogen immediately after young leaves were retrieved from the freezer, in order to prevent a loss of moisture that could make the leaves difficult to grind. The grinding step was repeated twice to obtain a fine powder. The Plant DNAzol Reagent (Invitrogen Corp., Carlsbad, CA, USA) and its instruction manual were employed for the fine power with minor modifications for DNA extraction.

\section{AFLP procedure}

AFLP reactions were performed according to Vos et al. (1995) using an AFLP Core Reagent Kit and an AFLP Starter Primer Kit as per the manufacturer's instruction manual (Invitrogen Corp., Carlsbad, CA. USA). At pre- and selective amplification, one and three selective nucleotides were used, respectively. Eleven primer combinations were used in the selective amplification (Table 2). Amplified products were electrophoresed at $100 \mathrm{~V}$ for $9 \mathrm{~h}$ in polyacrylamide gels with Tris-Glycine buffer. The polyacrylamide gel consisted of a running gel (13\%) and a stacking gel (5\%), and was $16 \mathrm{~cm} \times 16 \mathrm{~cm} \times 0.8 \mathrm{~mm}$ in size. The AFLP products separated on the $13 \%$ polyacrylamide gels were detected by using Silver Staining Kit II (Wako, Japan).

\section{Data analysis}

The bands between $100-1,000 \mathrm{bp}$ on the polyacrylamide gels were manually scored as present (1) or absent (0). Unclear fragments were ignored. The frequency of a null allele at a given locus was estimated by taking the square root of the frequency of null homozygosity (i.e. absence of a band), which assumes that there are two alleles at a locus under the Hardy-Weinberg equilibrium. Based on the estimated frequency of a null allele, the frequency of heterozygosity $(H)$ within a population $(H s)$ and all individuals $(H t)$ were calculated. The genetic differentiation among populations (Gst) was calculated as (Ht - average Hs)/Ht (Nei 1973). NTSYSpc version 2.20 was used for the calculation of Nei's genetic distance (Nei 1972) between each individual, and the NJ method (Saitou $\&$ Nei 1987) was used for the construction of a phylogenetic tree. Bootstrap probability with 100 resamplings was used to assess the reliability of interior branches of the phylogenetic tree.

\section{Results}

In total, 242 AFLP loci were detected by using 11 primer combinations (Table 2). The number of detected AFLP loci/individual was between 214 and 231. Among the 242 loci, 57 loci (23.6\%) were polymorphic (Table 2). Except for population No. 1 and No. 2, polymorphism was detected within each population (Table 1). The percentage of the number of polymorphic loci within a population ranged from 0.00 (No. 1) to $9.50 \%$ (No. 16). By comparing the percentage of the number of polymorphic loci within a population among the three regions, the highest frequency of polymorphism was found in

Table 2. Primer combinations and number of detected loci

\begin{tabular}{cccc}
\hline \hline Primer & Number of total loci & $\begin{array}{c}\text { Number of polymorphic } \\
\text { loci }\end{array}$ & \% of polymorphic loci \\
\hline E-ACA, M-CAT & 19 & 4 & 21.1 \\
E-ACG, M-CTA & 13 & 7 & 53.8 \\
E-AGG, M-CTC & 26 & 4 & 15.4 \\
E-ACC, M-CAG & 19 & 2 & 10.5 \\
E-ACC, M-CTT & 23 & 4 & 17.4 \\
E-ACG, M-CAC & 15 & 7 & 46.7 \\
E-AAG, M-CTC & 21 & 1 & 4.8 \\
E-ACG, M-CAT & 18 & 10 & 55.6 \\
E-AAC, M-CAC & 31 & 9 & 29.0 \\
E-ACC, M-CTC & 24 & 6 & 25.0 \\
E-AAC, M-CAG & 33 & 3 & 9.1 \\
Total & 242 & 57 & 23.6 \\
\hline
\end{tabular}


Table 3. Genetic diversity within each region

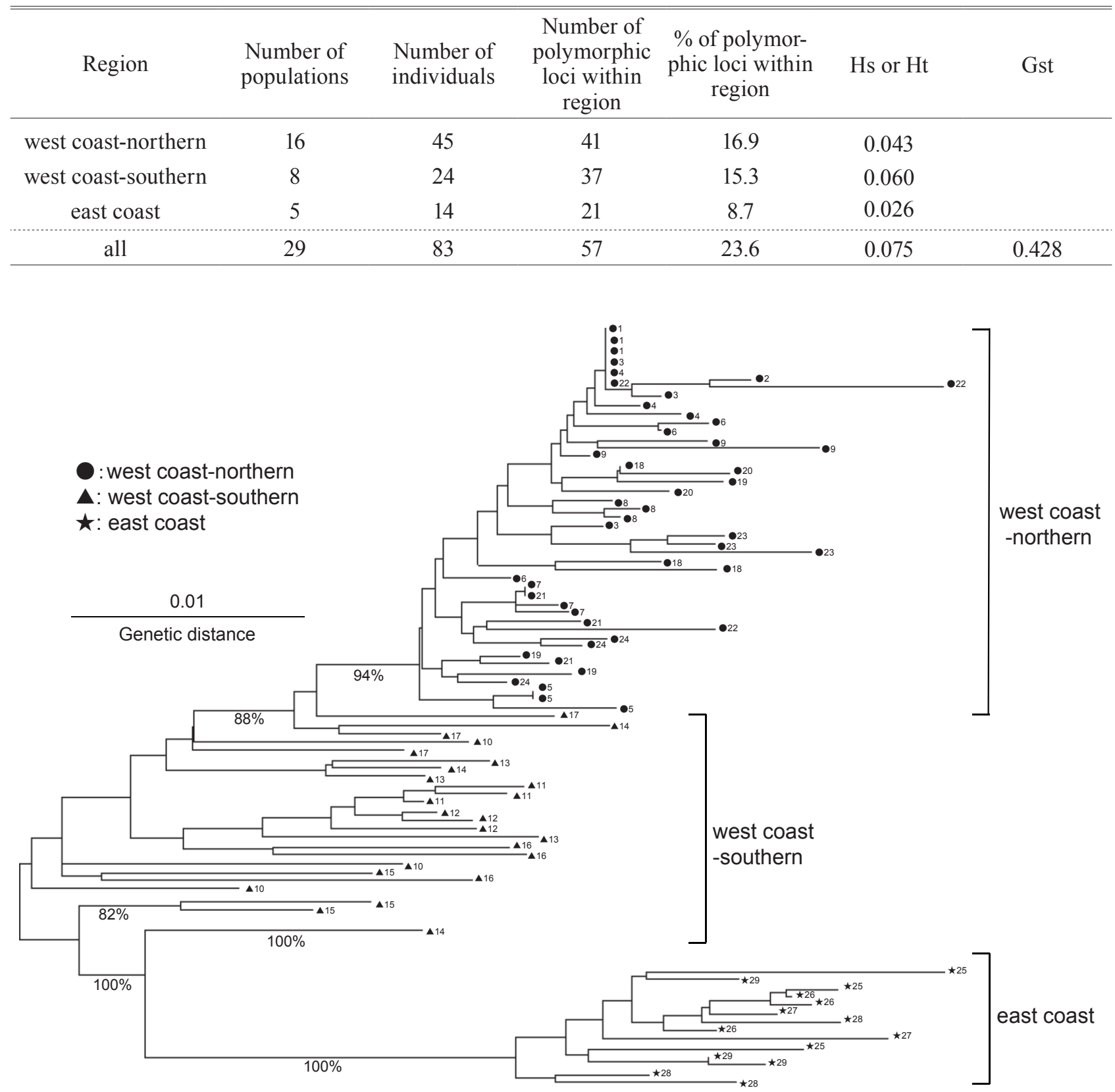

Fig. 2. Neighbor-joining tree based on AFLP markers. Bootstrap values greater than $80 \%$ are provided for the branches.

the west coast southern region $(6.35 \pm 2.97)$, followed by the east coast region $(3.31 \pm 1.40)$, and with the lowest frequency being in the west coast northern region (2.18 \pm 1.40 ). Polymorphism was also detected within each region (Table 3). The results also showed that the west coast southern region had the highest $H s$ among the three regions (0.060), while $H s$ of the west coast northern region was 0.043 and that of the east coast region was 0.026 . $H t$ was 0.075 and Gst on these three geographic groups was 0.428 . In contrast, the percentage of the number of polymorphic loci within a region was highest in the west coast northern region $(16.9 \%, \mathrm{n}=45)$, followed by the west coast southern region $(15.3 \%, \mathrm{n}=24)$, and with the lowest in the east coast region $(8.7 \%, n=14)$. A phylogenetic tree was constructed using the NJ method (Fig. 2). The results clearly demonstrated that all individuals in each of the three geographic regions clustered together in their respective groups. In terms of their phylogenetic relationships, the east coast region formed a genetically distinct group based on its genetic distance from individuals in 
the west coast region, which is supported by a $100 \%$ bootstrap value. The two western coast groups were also differentiated, which is supported by a $94 \%$ bootstrap value. The group of the west coast southern region involved individuals that are closer genetically to the group of the west coast northern region group and the east coast region group. One individual of population No. 14 and two individuals of population No. 15 were closer to the east coast region group, which is supported by $100 \%$ and $82 \%$ bootstrap values, respectively. Two individuals of population No. 17 and one individual of population No. 14 were closer to the west coast northern region group, which is supported by an $88 \%$ bootstrap value.

\section{Discussion}

\section{Genetic diversity within a population}

Previous studies on the genetic diversity of nipa populations reported no or low polymorphism within a population. Jian et al. (2010) analyzed 183 individuals from six populations in Vietnam, Thailand, and southern China by using 40 ISSR primers and 17 SSR markers. As a result, the ISSR primers detected no polymorphism within a population and the SSR markers only detected polymorphism in a population. Setoguchi et al. (1999) analyzed 28 individuals from a population on Iriomote Island (where nipa is an endangered species) by using 20 RAPD primers, and reported that only one individual showed low polymorphism. Setoguchi et al. (1999) also concluded that this result suggests the population consists of clones derived from a single original individual, which will be exterminated in the near future due to the difficulty of producing fertile seeds by outcrossing.

Although only two or three individuals per population were analyzed in this study, 27 out of 29 populations showed polymorphism within a population, ranging from 0 to 23 polymorphic loci within populations (Table 1). This result may suggest two things, one is that the nipa population in Peninsular Malaysia possesses high genetic diversity and/or that the AFLP markers used in this study are more useful in detecting polymorphism than the RAPD, ISSR, and SSR markers previously used. The revealed polymorphism within a population might suggest that individuals in each population propagate not only by rhizome growth but also by seed germination, thereby adding more diversity. This polymorphism within a population and the propagation system can provide the nipa habitats in Peninsular Malaysia with better adaptability and survival in response to environment changes.

\section{Genetic diversity within a region and geographical differentiation}

The frequency of heterozygosity within a region $(H s)$ was highest in the west coast southern region (0.060), suggesting that this region may be the center of nipa genetic diversity in Peninsular Malaysia. The mean percentage of polymorphic loci within the populations in this region is also higher than that of the west coast northern region and the east coast. The lower value of $H_{s}$ in the west coast northern region (0.043) and even lower value in the east coast region (0.026) might be the result of nipa populations having been diffused along the coastal area extending from the west coast southern region. It is easy to visualize that individuals from the southern region of the west coast can be naturally disseminated to the northern region along the coastline in the old period, but more difficult to the east coast due to a longer geographic distance from the west coast. In addition, the end of the Malay Peninsula area adjacent to Singapore might be developed industrially through the ages, and could also be a barrier for the diffusion of nipa from the west coast to the east coast.

Though the percentage of polymorphic loci within a region was higher in the west coast northern region $(16.9 \%, \mathrm{n}=45)$ than in the west coast southern region $(15.3 \%, \mathrm{n}=24)$, this result might be effected by about twice the number of individuals in the west coast northern region.

The frequency of heterozygosity in other nipa populations ( $\mathrm{n}=27$ to 33 ) was calculated based on SSR markers (Jian et al. 2010). Hs was 0.000 for four populations in southern China and one population in Vietnam, as these populations were monomorphic. $H s$ was 0.042 for a population collected from the root area of the Malay Peninsula in Thailand. The $H s$ value of the population is at the same level as that of the west coast northern region in this study (0.043). These results might suggest that the Malay Peninsula as whole (not only in Peninsular Malaysia) may possess high levels of nipa genetic diversity. It would now be interesting to survey the areas between Peninsular Malaysia and the Malay Peninsula of Thailand, in order to better understand the extent and distribution of genetic resources of nipa in the Malay Peninsula.

We cannot conclude that genetic diversity of nipa is higher in Peninsular Malaysia than in southern China and Vietnam, however, due to an evaluation of genetic diversity based on different DNA markers, that is, SSR (Jian et al. 2010) and AFLP. In the future, analyzing the nipa populations in not only southern China and Vietnam but also in other regions (e.g., Indonesia, Thailand, Cambodia, Myanmar) based on AFLP markers may be 
more useful than SSR markers to detect polymorphism, thereby revealing the genetic diversity center of nipa.

The frequency of heterozygosity was also calculated based on AFLP markers for other species. For example, mangrove plants-Avicennia marina (Forsk.) Vierh, in Vietnam-were analyzed for six populations $(\mathrm{n}=11$ to 25) (Giang et al. 2003). Hs ranged from 0.037 to 0.083 and $H t$ was 0.086 . These values were smaller in this study, where $H s$ ranged from 0.024 (east coast region) to 0.060 (west coast southern region) and $H t$ was 0.075 . This result might relate to the reproductive methods of the plants, and may be due to the predominantly vegetative propagation system of nipa as compared with other mangrove species.

However, nipa populations analyzed in this study showed a higher Gst value (0.428) as compared to mangrove species (Avicennia marina) populations in Vietnam (0.262) that were calculated based on AFLP data (Giang et al. 2003). It is possible that nipa populations in Peninsular Malaysia have differentiated genetically within each region, such that there is a high value between population diversity. This calls for many nipa populations across the range to become targets for conservation. A conservation strategy should take this distribution into account and ensure that the maximum numbers of habitats are conserved in situ. Habitats for in situ conservation should be selected from the west coast northern region, west coast southern region, and the east coast, respectively, as populations among these three regions are highly differentiated genetically. Those populations where in situ measures are not possible should be collected and established in ex situ collections. For ex situ conservation, we should also collect samples from the west coast northern region, west coast southern region, and the east coast, respectively. Such a strategy would ensure that the genetic diversity of nipa is well conserved.

\section{Phylogenetic relationships}

The individuals in the east coast region formed a group that is genetically distinct from individuals on the west coast, which is supported by a $100 \%$ bootstrap value (Fig. 2). The west coast populations were also differentiated genetically between the northern and southern regions, which is supported a $94 \%$ bootstrap value (Fig. 2). Our field survey on nipa habitats in Peninsular Malaysia, the Global Land Survey, and the Landsat archives on mangrove forests in the world (Giri et al. 2011) revealed that only a few nipa habitats exist on the west coast of the states of Negri Sembilan and Selangor, and on the east coast of the Johor area. We supposed that these geographical gaps among the west coast northern, west coast southern, and east coast regions caused genetic differentiation among the three regions, based on a report suggesting that geographical gaps caused genetic differentiation on a mangrove genus. Mangrove genus Kendelia, which is distributed from southern Japan to India through southern China and Southeast Asia, is distinguished into two species (Sheue et al. 2003). One species ( $K$. obovata) is distributed from southern Japan to southern China, while the other species (K. candel) is distributed from Southeast Asia to India, with few habitats of this genus being reported along the coastal area of Vietnam (Sheue et al. 2003). Interrupted distribution of the genus in the coastal area of Vietnam might have accelerated genetic differentiation and caused the differentiation of $K$. obovata and $K$. candel. We suppose that geographical gaps are among the most powerful causes of accelerating genetic differentiation for mangrove species.

Regarding the diffusion of nipa in Peninsular Malaysia, we conclude that nipa was diffused along coastal areas, but not through inland areas. Populations in the west coast southern region involve individuals that are genetically closer to the east coast region (population No. 14 and No. 15), as well as the west coast northern region (population No. 14 and No. 17). Therefore, the nipa populations in Peninsular Malaysia might be diffused from or through the west coast southern region.

\section{References}

Baja-Lapis, A. C. et al. (2004) Nypa fruticans Wurmb. In ASEAN's 100 most precious plants, eds. Uritarte, M. T. \& Lopez, E. M., The European Commission, Makati, Philippines, 208-209.

Brukill, I. H. (1935) Nipa. In: A dictionary of the economic products of the Malay Peninsula, Vol. II, ed. Malaysia's Ministry of Agriculture, Crown Agents for the Colonies, London, UK. 1557-1561.

Corner, E. J. H. (1966) The natural history of palms. Weidenfeld and Nicholson, London, UK.

Fong, F. W. (1984) Nipa swamps-a neglected mangrove resource. In: Proc. Asian symposium on mangrove environment: research and management, August 1980, ed. Soepadmo, E., Univ. of Malaya, Kuala Lumpur, Malaysia, 663-671.

Fong, F. W. (1992) Perspective for sustainable resource utilization and management of nipa vegetation. Economic Botany, 46, 45-54.

Giang, L. H. et al. (2003) Genetic variation of Avicennia marina (Forsk.) Vierh. (Avicenniaceae) in Vietnam revealed by microsatellite and AFLP markers. Genes Genet. Syst., 78, 399-407.

Giri, C. et al. (2011) Status and distribution of mangrove forests of the world using earth observation satellite data. Global. Ecol. Biogeogr., 20, 154-159.

Hamilton, L. S. \& Murphy, D. H. (1988) Use and management of nipa palm (Nypa fruticans, Arecaceae): a review. Economic Botany, 42, 206-213. 
Ilias, G. N. M. et al. (2002) Study on CCB (Chromated Copper Boric Acid) dip preservation of Golpata (Nypa fruticans). Pertanika J. Sci. Technol., 10, 201-208.

Jian, S. et al. (2010) Low genetic variation detected within the widespread mangrove species Nypa fruticans (Palmae) from Southeast Asia. Aquatic Botany, 92, 23-27.

Nei, M. (1972) Genetic distance between populations. Amer. Naturalist, 106, 283-292.

Nei, M. (1973) Analysis of gene diversity in subdivided populations. Proc. Nat. Acad. Sci. USA, 70, 3321-3323.

Päiväke, A. E. A. (1996) Nypa fruticans Wurmb. In: Plant resource of Southeast Asia No. 9: Plant yielding non-seed carbohydrates. ed. Flach, M. \& Rumawas, F., Prosea Foundation, Bogor, Indonesia, 133-137.

Robillos, Y. U. (1978) The nipa shingle industry of Batangas. Forpride Digest, 7, 58-66.

Robinson, C. B. (1911) Philippine hat. Philipp. J. Sci., Series C
6, 93-129.

Saitou, N. \& Nei, M. (1987) The neighbor joining method: A new method for reconstructing phylogenetic trees. Mol. Biol. Evol., 44, 406-425.

Setoguchi, H. et al. (1999) Genetic diversity of the natural monument Nypa fruticans (Palmae) at Funaura, Iriomote Island. Acta Geobot. Phytotax., 50, 201-205.

Sheue C. R. et al. (2003) Kandelia obovata (Rhizophoraceae), a new mangrove species from Eastern Asia. Taxon, 52, 287294.

Tomlinson, P. B. (1986) The Botany of Mangroves. Cambridge University Press, Cambridge, UK.

Vos, P. et al. (1995) AFLP, a new technique for DNA fingerprinting. Nucleic Acids Res., 23, 4407-4414.

Whitmore, T. C. (1973) Palms of Malaysia. Oxford University Press, London, UK. 